\title{
Características e efeitos da fototerapia em recém-nascidos: revisão integrativa
}

\author{
Characteristics and effects of phototherapy in newborn: integrative review \\ Características y efectos de la fototerapia en recién nacidos: una revisión integradora
}

\section{Resumo}

O presente trabalho tem como objetivo analisar as evidências científicas acerca das características e efeitos da fototerapia em recém-nascidos. Trata-se de um estudo de revisão integrativa de literatura, realizada nas bases de dados Literatura Latino Americana e do Caribe em Ciências de Saúde (LILACS), Sistema Online de Busca e Análise de Literatura Médica (MEDLINE) e Web of Science, com estratégias de busca com Descritores de Ciências da Saúde (DECS) e Medical Subject Headings (MeSH). Foram selecionados para análise 19 artigos no período entre 2011 a 2019, a partir da questão de revisão e dos critérios de inclusão. A análise dos estudos revelou dentre as evidências científicas: os tipos de fototerapia, sendo: convencional, diodo emissor de luz (LED), LED dupla, contínua e intermitente. E, a outra evidência encontrada foi acerca dos efeitos e usos da fototerapia, como: a variabilidade da frequência cardíaca, estresse oxidativo, diminuição da globulina sérica, hipocalcemia, epilepsia, aumento de metabólitos. A fototerapia é benéfica, pois degrada a bilirrubina sérica evitando complicações como a Síndrome de Kernicterus. Porém, o seu uso indiscriminado deve ser revisto e sua utilização necessita ser criteriosa para evitar a sessões de fototerapia em casos em que a bilirrubina não tenha atingido os níveis recomendados. Destaca-se a atuação da enfermagem no cuidado ao recém-nascido em fototerapia e necessita ter sua prática pautada em evidências científicas, uma vez que qualifica e humaniza o cuidado a partir das necessidades biopsicossociais, além desta qualificação permitir a melhor escolha de assistência ao recém-nascido e sua família.

Palavras-chave: Recém-nascido; Fototerapia; Enfermagem.

\footnotetext{
Abstract

This study aims to analyze the scientific evidence about the characteristics and effects of phototherapy in newborns. This is an integrative literature review, carried out in databases of Latin American and Caribbean Health Sciences Literature (LILACS), Medical Literature Analysis and Retrieval System Online (MEDLINE) and Web of Science,
} 
with search strategies with Health Sciences Descriptors (DECS) and Medical Subject Headings (MeSH). Nineteen articles between 2011 and 2019 were selected for analysis, based on the review question and inclusion criteria. The analysis of the studies revealed as one of the scientific evidences, the types of phototherapy: conventional, light emitting diode (LED), double LED, continuous and intermittent. The other evidence found was the effects and uses of phototherapy, such as: heart rate variability, oxidative stress, decreased serum globulin, hypocalcemia, epilepsy, increased metabolites. Phototherapy is beneficial because it degrades serum bilirubin, preventing complications such as kernicterus. However, its indiscriminate use should be reviewed and its use needs to be careful to avoid the realization of phototherapy sessions if bilirubin has not reached the recommended levels. Thus, it is emphasized that nursing acts in care of the newborn in phototherapy and need to have their practice based on scientific evidence, since it qualifies and humanizes care based on biopsychosocial needs. In addition, this qualification allows the best choice of assistance to the newborn and his family.

Keywords: Newborn; Phototherapy; Nursing.

\section{Resumen}

El presente trabajo tiene como objetivo analizar las evidencias científicas sobre las características y efectos de la fototerapia en recién nacidos. Se trata de un estudio de revisión integradora de la literatura, realizado en las bases de datos de Literatura Latinoamericana y Caribeña en Ciencias de la Salud (LILACS), Sistema Online de Búsqueda y Análisis de Literatura Médica (MEDLINE) y Web of Science, con estrategias de búsqueda con Descriptores de Ciencias de la Salud (DECS) y Medical Subject Headings (MeSH). Se seleccionaron diecinueve artículos para su análisis entre 2011 y 2019, según la pregunta de revisión y los criterios de inclusión. El análisis de los estudios reveló entre las evidencias científicas: los tipos de fototerapia, siendo: convencional, diodo emisor de luz (LED), doble LED, continua e intermitente. Y, la otra evidencia encontrada fue sobre los efectos y usos de la fototerapia, tales como: variabilidad de la frecuencia cardíaca, estrés oxidativo, disminución de globulina sérica, hipocalcemia, epilepsia, aumento de metabolitos. La fototerapia es beneficiosa porque degrada la bilirrubina sérica y previene complicaciones como el kernicterus. Sin embargo, se debe revisar su uso indiscriminado, y su uso debe ser juicioso para evitar sesiones de fototerapia si la bilirrubina no ha alcanzado los niveles recomendados. Así, se destaca que la enfermería trabaja en el cuidado del recién nacido en fototerapia y necesita tener su práctica basada en evidencias científicas, ya que califica y humaniza el cuidado basado en necesidades biopsicosociales, además de esta cualificación permitir a la mejor elección de asistencia al recién nacido y su familia.

Palabras clave: Recién nacido; Fototerapia; Enfermería.

\section{Introdução}

A Organização Mundial da Saúde (OMS) define cronologicamente o recém-nascido menor ou igual a 28 dias. Nesse período, há maior risco de mortalidade neonatal e complicações neonatais, pois é necessária a adaptação do recém-nascido à vida extrauterina (OMS, 2018).

Entre as complicações neonatais, tem-se a icterícia que se caracteriza pela cor amarelada na pele e mucosas sendo causada pela quantidade maciça de bilirrubina na circulação sanguínea, a hiperbilirrubinemia. É comum o surgimento da icterícia fisiológica em recém-nascidos após as primeiras 24 horas de vida, porém se ela surge ainda antes, pode ser considerada patológica (Saadat, et al.; 2018).

As causas da icterícia neonatal estão relacionadas a diversos fatores, como prematuridade do recém-nascido, sexo masculino, amamentação, diabetes gestacional, predisposição genética, infecções do grupo TORCH (toxoplasmose, rubéola, citomegalovírus, vírus da herpes), sepse, infecções do trato urinário, entre outras complicações que podem trazer riscos à saúde do recém-nascido (Carrasco Tejerina, 2016; Rebollar-Rangel, et al.; 2017; Campbell Wagemann, et al.; 2019).

Os manejos terapêuticos para a icterícia incluem o estímulo e encorajamento do aleitamento materno em livre demanda e a fototerapia no recém-nascido por meio do banho de luz, que promove a excreção da bilirrubina com a fotoisomerização. A fototerapia é um tratamento demorado e com algumas necessidades acerca do posicionamento, nudez e oclusão ocular dos recém-nascidos, o que pode muitas vezes dificultar o vínculo mãe-bebê, pois essas necessidades delimitam as mamadas ao seio, o contato pele a pele e a interação pais-bebê. A fototerapia pode gerar isolamento social, diminuição dos estímulos neurossensitivos, alteração dos ritmos biológicos, alteração da alimentação e mudanças das atividades (Ramachandran, 2016; Santos, et al., 2018). 
Nessa direção, é fundamental ampliar o conhecimento a partir de evidencias científicas acerca da fototerapia, em prol da qualificação do cuidado de enfermagem ao recém-nascido e sua família (Fernandes, 2018). Portanto, tem-se como objetivo: analisar as evidências científicas acerca das características e efeitos da fototerapia em recém-nascidos.

\section{Metodologia}

Trata-se de uma pesquisa bibliográfica do tipo revisão integrativa (RI), a qual apresenta ampla abordagem metodológica, o que possibilita a inclusão de estudos experimentais e não-experimentais, proporcionando a síntese das evidências disponíveis acerca do tema ou questão pesquisada (Whittemore \& Knafl, 2005). Para o desenvolvimento desse estudo de revisão, buscou-se responder a seguinte questão: quais as evidências científicas relacionadas ao recém-nascido em fototerapia? As buscas ocorreram na base de dados Web of Science e no portal da Biblioteca Virtual de Saúde (BVS): Literatura Latino Americana e do Caribe em Ciências de Saúde (LILACS), Sistema Online de Busca e Análise de Literatura Médica (MEDLINE).

A estratégia utilizada para a busca nas bases de dados foi: "infant, newborn" AND "phototherapy". Teve-se como recorte temporal o ano de 2011 devido a publicação da primeira edição do Manual de Atenção à Saúde do Recém-Nascido: Guia para os Profissionais de Saúde, do Ministério da Saúde (Brasil, 2011) que tem o objetivo de atualizar os profissionais da saúde e promover atenção qualificada e segura ao recém-nascido. Entre os conteúdos abordados, tem-se a icterícia com a etiologia, tipos de hiperbilirrubinemia, conduta terapêutica, a exemplo da fototerapia, e o prognóstico.

A extração dos dados foi realizada a partir dos critérios de inclusão dos artigos: ser artigo de pesquisa; idioma inglês, espanhol ou português; artigo da temática e responder à pergunta de revisão. A pesquisa foi desenvolvida com o duplo dependente e com terceiro revisor, caso houvesse dúvidas entre os revisores que desenvolveram as buscas e realizaram as seleções. A seleção dos estudos ocorreu no segundo semestre de 2019.

Para avaliação crítica dos estudos primários, os artigos selecionados foram avaliados conforme um sistema classificador de força de evidência (Melnyk \& Fineout-Overholt, 2011). Na Figura 1, a seguir apresenta-se o fluxograma com as bases de dados pesquisadas, aplicação dos critérios de inclusão e reunião de consenso quando ocorreram divergências. 
Research, Society and Development, v. 10, n. 2, e19610212412, 2021

(CC BY 4.0) | ISSN 2525-3409 | DOI: http://dx.doi.org/10.33448/rsd-v10i2.12412

Figura 1. Fluxograma.

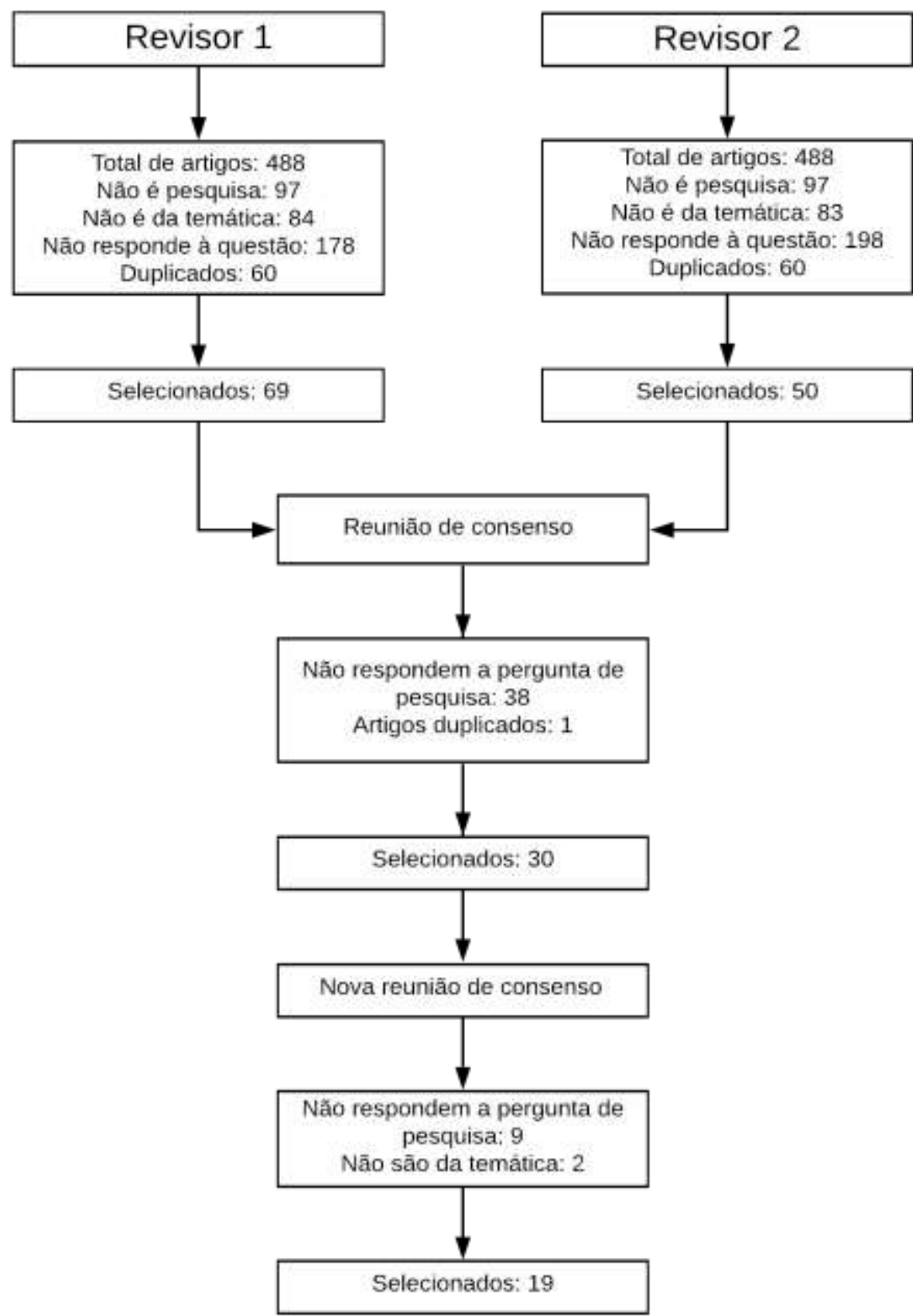

Fonte: Faria (2019).

Esse fluxograma apresenta as etapas realizadas, revisores envolvidos na seleção dos artigos, com momentos de reuniões de consenso quando ocorreram divergências. Cabe destacar, que é importante que os revisores tenham conhecimento acerca da temática, pois refletirá na qualidade dos resultados.

No Quadro 1 a seguir apresenta-se as produções que compuseram o corpus da pesquisa e a força e evidência de cada uma delas. 
Quadro 1. Quadro sinóptico das produções que compuseram o corpus da pesquisa e a classificação da força de evidência (LILACS, MEDLINE e Web of Science, 2011-2019).

\begin{tabular}{|c|c|c|c|}
\hline Autor & Objetivo & Resultados & $\begin{array}{l}\text { Nível de } \\
\text { evidência }\end{array}$ \\
\hline $\begin{array}{l}\text { 1. LUCIANO, R. et } \\
\text { al. }\end{array}$ & $\begin{array}{l}\text { Comparar a eficácia de dois dispositivos de } \\
\text { fototerapia (FPT), ambos equipados com um } \\
\text { único diodo emissor de luz (LED). }\end{array}$ & $\begin{array}{l}\text { Um dispositivo de fibra óptica de LED equipado com uma almofada envolvida em torno do } \\
\text { corpo do neonato para aumentar a superfície corporal exposta mostra redução horária do TSB } \\
\text { (taxa sérica de bilirrubina) semelhante, duração do FPT semelhante e redução percentual geral } \\
\text { do TSB do que um dispositivo de/com fibra óptica de LED de dois pads (fototerapia } \\
\text { dupla). Esses resultados foram obtidos em todos os neonatos do Grupo } 1 \text { tratados, sem os } \\
\text { efeitos colaterais (hipertermia) observados nos neonatos do Grupo 2, em que dois neonatos não } \\
\text { responderam ao tratamento. }\end{array}$ & $\mathrm{N} 3 *$ \\
\hline $\begin{array}{l}\text { 2. SACHDEVA, M. } \\
\text { et al. }\end{array}$ & $\begin{array}{l}\text { Saber se uma programação intermitente de } \\
12 \text { horas dentro e } 12 \text { horas fora da } \\
\text { fototerapia será tão eficaz quanto a } \\
\text { programação contínua no tratamento da } \\
\text { hiperbilirrubinemiamoderada em bebês } \\
\text { prematuros a termo e prematuros tardios. }\end{array}$ & $\begin{array}{l}\text { A taxa de queda de bilirrubina foi significativamente maior com a fototerapia intermitente (IPT) } \\
\text { em comparação com a fototerapia contínua (CPT). A duração mediana da fototerapia foi } \\
\text { significativamente menor no grupo IPT em comparação com o grupo CPT. A mediana do tempo } \\
\text { de internação, a taxa sérica de bilirrubina (TSB) e o número de neonatos que necessitaram de } \\
\text { readmissão não diferiram estatisticamente nos dois grupos. }\end{array}$ & $\mathrm{N} 2 *$ \\
\hline $\begin{array}{l}\text { 3. COLINDRES, J. } \\
\text { V. et al. }\end{array}$ & $\begin{array}{l}\text { Comparar a eficácia da fototerapia de LED } \\
\text { com a da fototerapia convencional. }\end{array}$ & $\begin{array}{l}\text { A fototerapia usando luzes LED de baixo custo foi tão eficaz quanto à terapia convencional } \\
\text { usando luzes fluorescentes azuis ou luzes de halogênio. }\end{array}$ & $\mathrm{N} 2 *$ \\
\hline $\begin{array}{l}\text { 4.MERITANO, J, et } \\
\text { al. }\end{array}$ & $\begin{array}{l}\text { Comparar a eficácia da fototerapia (FPT) em } \\
\text { termos de horas de tratamento entre tubos de } \\
\text { luz azul (convencional) e equipamentos de } \\
\text { LEDs com dois níveis de irradiância. }\end{array}$ & $\begin{array}{l}\text { Entre janeiro e julho de 2010, } 165 \text { pacientes foram incluídos, } 54 \text { no grupo } 1 \text { (luz azul, } \\
\text { irradiância de } 30 \mathrm{uW} / \mathrm{cm} 2 / \mathrm{nm} \text { ), } 56 \text { no grupo } 2 \text { (LEDs, irradiância de } 30 \mathrm{uW} / \mathrm{cm} 2 / \mathrm{nm} \text { ) e } 55 \\
\text { emgrupo } 3 \text { (LEDs, irradiância de } 40 \mathrm{uW} / \mathrm{cm} 2 / \mathrm{nm} \text { ).O tempo total em horas de fototerapia foi } \\
\text { menor no grupo } 3 . \text { O grupo } 3 \text { também obteve um decréscimo maior do nível total de bilirrubina. }\end{array}$ & $\mathrm{N} 2 *$ \\
\hline $\begin{array}{l}\text { 5. HAMIDI, M.; } \\
\text { ALIAKBARI, F. }\end{array}$ & $\begin{array}{l}\text { Comparar a segurança e eficácia do LED e } \\
\text { da fototerapia convencional no tratamento } \\
\text { da hiperbilirrubinemia. }\end{array}$ & $\begin{array}{l}\text { Os resultados denotam que as taxas séricas de bilirrubina (TSB) foram significativamente } \\
\text { menores no grupo LED em todos os momentos e com uma taxa mais descendente neste grupo. }\end{array}$ & $\mathrm{N} 2 *$ \\
\hline 6. DONNEBORG, & Investigar se a fototerapia dupla reduz a taxa & Os bebês tratados com fototerapia dupla diminuíram significativamente mais do que os bebês & $\mathrm{N} 2 *$ \\
\hline
\end{tabular}




\begin{tabular}{|c|c|c|c|}
\hline M. L. et al. & $\begin{array}{l}\text { de bilirrubina sérica (TSB) mais } \\
\text { rapidamente que a fototerapia única durante } \\
\text { a fototerapia intensiva com altos níveis de } \\
\text { irradiância usando LEDs. }\end{array}$ & $\begin{array}{l}\text { tratados com fototerapia única. Apesar de usar altos níveis de irradiância, não foram observados } \\
\text { efeitos colaterais da fototerapia além das fezes soltas. Nenhum bebê teve hipo ou hipertermia e } \\
\text { não foram observadas erupções cutâneas. }\end{array}$ & \\
\hline $\begin{array}{l}\text { 7. UHRIKOVA, Z. et } \\
\text { al. }\end{array}$ & $\begin{array}{l}\text { Investigar um efeito da hiperbilirrubinemia } \\
\text { no controle autonômico da frequência } \\
\text { cardíaca comparando os neonatos ictéricos } \\
\text { com sujeitos controle saudáveis; Investigar } \\
\text { um efeito da fototerapia na dinâmica da } \\
\text { frequência cardíaca, refletindo seu controle } \\
\text { no sistema nervoso autônomo. }\end{array}$ & $\begin{array}{l}\text { A análise linear convencional da variabilidade da frequência cardíaca (VFC) não revelou } \\
\text { diferença significativa entre recém-nascidos ictéricos e de controle, indicando que a } \\
\text { hiperbilirrubinemia não apresenta efeito sobre a magnitude da VCF. A vasodilatação periférica } \\
\text { e redução atividade motora de um bebê leva a uma redução no débito cardíaco } 30 \text { minutos após } \\
\text { a fototerapia, seguida pela ativação de mecanismos compensatórios autonômicos via } \\
\text { barorreflexo, resultando em redistribuição do fluxo sanguíneo e alterações da frequência } \\
\text { cardíaca. }\end{array}$ & $\mathrm{N} 2 * *$ \\
\hline $\begin{array}{l}\text { 8. MOKHTAR, W. } \\
\text { A. et al }\end{array}$ & $\begin{array}{l}\text { Investigar bebês com icterícia hemolítica } \\
\text { neonatal no que diz respeito ao tipo mais } \\
\text { seguro de fototerapia para esse tipo de } \\
\text { hiperbilirrubinemia neonatal. }\end{array}$ & $\begin{array}{l}\text { Após } 48 \text { horas de fototerapia, a capacidade antioxidante total (TAC) foi significativamente } \\
\text { menor nos dois grupos, com uma diminuição mais significativa no grupo } 1 . \text { O estresse oxidativo } \\
\text { total (TOS) e o índice de estresse oxidativo (OSI) aumentaram nos dois tipos de fototerapia, } \\
\text { com um aumento significativo no Grupo } 1 \text {. }\end{array}$ & $\mathrm{N} 2 *$ \\
\hline $\begin{array}{l}\text { 9. BOSKABADI, H.; } \\
\text { MOLAEI, M. K.; } \\
\text { ZAKERIHAMIDI, } \\
\text { M. }\end{array}$ & $\begin{array}{l}\text { Examinar os possíveis efeitos da fototerapia } \\
\text { no equilíbrio pró-oxidante/antioxi-dante } \\
\text { (PAB). }\end{array}$ & $\begin{array}{l}\text { Os resultados desse estudo indicaram um distúrbio na PAB como resultado da redução dos } \\
\text { níveis de bilirrubina. Os resultados desse estudo sugerem que níveis reduzidos de bilirrubina } \\
\text { após a fototerapia causam uma mudança nos valores de PAB a favor dos oxidantes. }\end{array}$ & N3* \\
\hline 10. KALE, Y. et al. & $\begin{array}{l}\text { Investigar os efeitos da fototerapia apli-cada } \\
\text { com diferentes fontes de luz no status global } \\
\text { de oxidante/antioxi-dante em neonatos. }\end{array}$ & $\begin{array}{l}\text { Tanto a fototerapia convencional quanto a fototerapia intensiva por LED diminuíram } \\
\text { significativamente a capacidade antioxidante total (TAC) sérico e aumentaram o status oxidante } \\
\text { total (TOS). Houve uma correlação fraca, mas significativa, entre o declínio no nível sérico de } \\
\text { bilirrubina total (STB) e o decréscimo na TAC. O TOS sérico foi aumentado após a fototerapia } \\
\text { convencional e fototerapia intensiva por LED com altas irradiâncias e, em menor grau, após a } \\
\text { fototerapia intensiva por LED com baixas irradiâncias. O Índice de estresse oxidativo (OSI) } \\
\text { aumentou em todos os pacientes após } 24 \text { horas de fototerapia. }\end{array}$ & N3* \\
\hline 11. ZHENG, J., et al & $\begin{array}{l}\text { Avaliar os efeitos da fototerapia como fator } \\
\text { de risco na diminuição dos níveis séricos de }\end{array}$ & $\begin{array}{l}\text { Os níveis séricos de globina (GLB) diminuem em resposta à fototerapia intensiva, com ou sem } \\
\text { infusão de albumina (IVALB) em recém-nascidos a termo com hiperbilirrubinemia. A }\end{array}$ & N4* \\
\hline
\end{tabular}




\begin{tabular}{|c|c|c|c|}
\hline & $\begin{array}{l}\text { globulina } \quad \text { (GIB) durante a } \\
\text { hiperbilirrubinemia neonatal. }\end{array}$ & $\begin{array}{l}\text { fototerapia acelera a depleção de GLB sérica, o que implica que os bebês que recebem } \\
\text { fototerapia têm um risco aumentado de imunossupressão, principalmente em recém-nascidos } \\
\text { com idade > } 16 \text { dias. O tratamento adicional com IVALB promoveu essa diminuição, } \\
\text { juntamente com o aumento da idade. }\end{array}$ & \\
\hline $\begin{array}{l}\text { 12. PADIPPURA; et } \\
\text { al. }\end{array}$ & $\begin{array}{l}\text { Avaliar a incidência de hipocalcemia por } \\
\text { fototerapia em recém-nascidos a termo e } \\
\text { hipocalcemia sintomática por fototerapia. }\end{array}$ & $\begin{array}{l}\text { Após } 48 \text { horas de fototerapia, } 43 \text { bebês }(26,1 \%) \text { desenvolveram hipocalcemia, mas apenas } 2 \\
\text { foram sintomáticos }(1,2 \%) \text {. O sintoma desenvolvido nesses dois casos foi o nervosismo. }\end{array}$ & N3* \\
\hline 13. NEWMAN, et al. & $\begin{array}{l}\text { Procuramos investigar a associação entre } \\
\text { fototerapia e o desenvolvimento de } \\
\text { convulsões e epilepsia no estudo LIGHT, } \\
\text { controlando os níveis de bilirrubina e outros } \\
\text { potenciais fatores de confusão. }\end{array}$ & $\begin{array}{l}\text { Das } 496.632 \text { crianças da coorte, } 37.683(7,6 \%) \text { receberam fototerapia. O desfecho primário de } \geq \\
1 \text { diagnóstico de convulsão e } \geq 1 \text { prescrição de medicamentos antiepilépticos (DAE) ocorreu em } \\
3.153(0,63 \%) \text { indivíduos. As taxas de incidência bruta por } 1.000 \text { pessoas-ano foram } 1,24 \text { entre } \\
\text { as expostas à fototerapia e } 0,76 \text { entre as não expostas. O sexo masculino em si foi associado a } \\
\text { um aumento de aproximadamente } 20 \% \text { no risco de convulsões. }\end{array}$ & $\mathrm{N} 1 * *$ \\
\hline 14. CAI, A. et al. & $\begin{array}{l}\text { Descrever as características metabólicas } \\
\text { séricas dos pacientes com icterícia neonatal } \\
\text { em relação aos controles e alterações em } \\
\text { resposta à fototerapia }\end{array}$ & $\begin{array}{l}\text { Os pacientes com icterícia neonatal apresentaram aumento de valina, mio-inositol, lisina, } \\
\text { leucina, lactato, isoleucina, alanina, creatina e glicina, bem como diminuição do colesterol de } \\
\text { lipoproteína de baixa densidade (LDL). Conjecturamos que os níveis mais altos observados de } \\
\text { creatina podem resultar da disfunção das células hepáticas. }\end{array}$ & N3* \\
\hline $\begin{array}{l}\text { 15. ZARKESH, M. et } \\
\text { al }\end{array}$ & $\begin{array}{l}\text { Investigar o efeito da fototerapia neonatal no } \\
\text { nível sérico de interleucina-6 (IL) e } \\
\text { contagem de leucócitos em neonatos } \\
\text { saudáveis com hiperbilirrubinemia. }\end{array}$ & $\begin{array}{l}\text { Houve aumento entre a contagem de leucócitos e os níveis de IL-6 antes e após a fototerapia. Os } \\
\text { níveis médios de IL-6 após a fototerapia aumentaram significativamente nos casos com idade } \\
<7 \text { dias. Portanto, parece que o TP pode alterar a função do sistema imunológico infantil. }\end{array}$ & N3* \\
\hline 16.SAJID, A. et al. & $\begin{array}{l}\text { Determinar o efeito da fototerapia na } \\
\text { contagem de plaquetas de recém-nascidos } \\
\text { hiperbilirrubinêmi-cos }\end{array}$ & $\begin{array}{l}\text { Após a continuação da fototerapia por } 24 \text { horas, cerca de } 8,1 \% \text { dos pacientes apresentavam } \\
\text { trombocitopenia grave (contagem de plaquetas }<50 \times 109 / \mathrm{L} \text { ), o número aumentou } \\
\text { gradualmente para } 18,4 \% \text { após } 48 \text { horas e } 33,3 \% \text { após } 72 \text { horas de fototerapia. Da mesma } \\
\text { forma, após } 24 \text { horas de fototerapia, } 50 \% \text { do total de pacientes não tiveram trombocitopenia, } \\
\text { esse número diminuiu para } 38 \% \text { após } 48 \text { horas e } 33 \% \text { após } 72 \text { horas após a conclusão da } \\
\text { fototerapia. }\end{array}$ & N3* \\
\hline $\begin{array}{l}\text { 17. NEWMAN, T. B. } \\
\text { et al. }\end{array}$ & $\begin{array}{l}\text { Investigar a associação entre o uso de } \\
\text { fototerapia neonatal e o câncer infantil. }\end{array}$ & $\begin{array}{l}\text { Houve } 60 \text { casos de câncer ( } 24,6 \text { por } 100.000 \text { pessoas-ano) entre crianças expostas à fototerapia, } \\
\text { em comparação com } 651 \text { casos ( } 17,2 \text { por } 100.000 \text { pessoas-ano) entre crianças não expostas. A } \\
\text { síndrome de Down foi um poderoso fator de risco para qualquer câncer e leucemia. A }\end{array}$ & $\mathrm{N} 1 * *$ \\
\hline
\end{tabular}




\begin{tabular}{|c|c|c|c|}
\hline & & $\begin{array}{l}\text { fototerapia foi associada a taxas aumentadas de qualquer leucemia, leucemia não linfocítica e } \\
\text { câncer de fígado. }\end{array}$ & \\
\hline $\begin{array}{l}18 . \\
\text { WICKREMASINGH } \\
\text { E, A. C. et al. }\end{array}$ & $\begin{array}{l}\text { Determinar se a fototerapia neonatal está } \\
\text { associada ao câncer no primeiro ano após o } \\
\text { nascimento. }\end{array}$ & $\begin{array}{l}1.100 \text { crianças foram diagnosticadas com câncer, resultando em uma incidência populacional } \\
\text { total de } 21,4 \text { / } 100.000 \text {. A própria icterícia foi associada a um risco aumentado de câncer, } \\
\text { controlando a fototerapia. Encontrou-se associações entre a fototerapia e o câncer em geral, } \\
\text { leucemia mielóide, câncer renal. Após o ajuste apenas para icterícia, a associação entre } \\
\text { fototerapia e leucemia mielóide foi semelhante, já as associações entre fototerapia e câncer geral } \\
\text { e outro câncer diminuíram ligeiramente, e a associação entre fototerapia e câncer renal diminuiu } \\
\text { ainda mais. O aumento do risco para o câncer após a fototerapia foi muito maior em bebês com } \\
\text { síndrome de Down }(77,8 / 100.000) \text { do que em lactentes sem síndrome de Down }(8,1 / 100 \text { 000). }\end{array}$ & $\mathrm{N} 4 * *$ \\
\hline 19. YAHIA, S. et al & $\begin{array}{l}\text { Avaliar o impacto da hiperbilirrubinemia e } \\
\text { fototerapia no dano ao DNA e apoptose nos } \\
\text { linfócitos do sangue periférico em bebês } \\
\text { saudáveis a termo. }\end{array}$ & $\begin{array}{l}\text { Correlações positivas significativas entre a duração da fototerapia e marcadores de dano ao } \\
\text { DNA [momento da cauda }(\mathrm{r}=0,31, \mathrm{p}=0,03), \% \text { de DNA na cauda }(\mathrm{r}=0,33, \mathrm{p}=0,02)] \text { e } \\
\text { marcadores de apoptose }[\mathrm{P} 53(\mathrm{r}=0,45, \mathrm{p}=0,002)] \text {. Achado interessante é o aumento } \\
\text { significativo de apoptose, conforme indicado por um aumento significativo de P53 induzido por } \\
\text { fototerapia; por outro lado, a hiperbilirrubinemia não influenciou os níveis de P53, dano ao } \\
\text { DNA ou apoptose dos linfócitos. }\end{array}$ & N3* \\
\hline
\end{tabular}

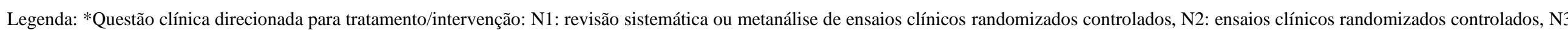

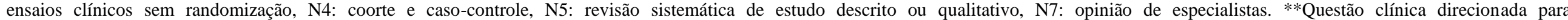

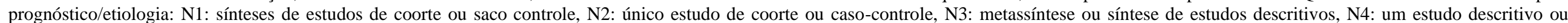
qualitativo, N5:opinião de especialistas. Fonte: Faria (2019). 
O quadro acima apresenta o corpus da pesquisa que consisti nos autores, objetivo, resultados e nível de evidência da pesquisa selecionada a partir dos critérios de inclusão. A partir das leituras dessas informações identificou-se o que tem sido pesquisado na temática de fototerapia em recém-nascidos.

\section{Resultados e Discussão}

Quanto à caracterização dos artigos selecionados, a maior parte dos estudos foi de abordagem quantitativa (89,5\%). Os cenários mais descritos foram Hospitais /Maternidades/ UTI Neonatal (89,5\%). A área de conhecimento encontrada nos 19 artigos foi a área da saúde (100\%). Os participantes foram recém-nascidos a termo e pré-termo moderado a tardio (42\%). A enfermidade predominante nos recém-nascidos foi a hiperbilirrubinemia $(89,5 \%)$. O aparelho de fototerapia que predominou nos estudos foi o de fototerapia convencional $(31,6 \%)$.

Para classificação da força das evidências, os estudos primários apresentaram questões direcionadas para o tratamento e intervenção e para o prognóstico ou etiologia na área da saúde (Melnik \& Fineout-Overholt, 2011). A maioria dos estudos correspondem a questões sobre o tratamento e intervenção com a realização de ensaios clínicos randomizados controlados ou ensaios clínicos sem randomização

Os tipos de fototerapia citados foram os modelos Bilisoft, GE Health Care (dispositivo A) e BiliCocoon, CremascolieIris (dispositivo B). O dispositivo A age como uma fototerapia dupla, pois envolve o corpo do recém-nascido por completo além de permitir que ele fique junto da mãe e receba leite materno em livre demanda. Já o dispositivo B também age como fototerapia dupla, porém, como possui maior adesão à pele do recém-nascido, houve casos de hipertermia, além de dois recém-nascidos serem excluídos do estudo por não responderem ao tratamento (Luciano et al., 2019).

Outro estudo trouxe a fototerapia por LED simples, aplicada acima do recém-nascido, e a fototerapia por LED dupla, um cobertor de fibra óptica inserido abaixo do recém-nascido, com resultados da bilirrubina sérica após 12 horas de exposição à luz, diminuídos 30\% com fototerapia simples e 39\% da dupla. Com 24 horas de exposição na fototerapia simples, ocorreu o decréscimo de bilirrubina sérica de $47 \%$, e $58 \%$ na fototerapia dupla (Donneborg, et al.; 2018). Em relação ao uso da fototerapia com LED simples ou dupla, foi evidenciado nos dois estudos que a fototerapia com LED dupla promove o decréscimo dos níveis séricos de bilirrubina mais rapidamente do que a fototerapia com LED simples (Donneborg, et al., 2018; Luciano, et al., 2019).

A fototerapia intermitente ou contínua foi comprovada em um estudo realizado em recém-nascidos pré-termos moderados a tardios e a termos randomizados que foram expostos à fototerapia por LED contínua (CPT) ou fototerapia por LED intermitente (IPT) de 12 em 12 horas, em que o grupo IPT obteve um declínio maior da taxa dos níveis séricos de bilirrubina e também menor duração do tratamento em comparação com o grupo CPT (Sachdeva, et al.; 2015).

Em um estudo comparando a eficácia da fototerapia com luz halógena, fluorescente e com LED de baixo custo foi comprovado que as três formas de fototerapia foram eficazes na redução dos níveis séricos de bilirrubina e também não diferiram no tempo de tratamento (Colindres et al., 2012). A ideia desse estudo foi viabilizar a fototerapia em lugares menos favorecidos, pois o aparelho construído pelos próprios autores é de baixo custo de construção e manutenção, além de possuir os mesmo benefícios de aparelhos mais caros (Colindres, et al., 2012).

Foi verificado em dois estudos que a fototerapia por LED diminuiu mais rapidamente a taxa de bilirrubina sérica e também diminuiu o tempo de exposição do recém-nascido à fototerapia (Meritano, et al., 2012; Hamidi, et al.; 2018). O estudo contou com três grupos diferentes: o grupo 1 recebeu fototerapia convencional de irradiância $30 \mathrm{uW} / \mathrm{cm} 2 / \mathrm{nm}$, grupo 2 fototerapias de LED com irradiância de $30 \mathrm{uW} / \mathrm{cm} 2 / \mathrm{nm}$, e o grupo 3 fototerapias de LEDs com irradiância de $40 \mathrm{uW} / \mathrm{cm} 2 / \mathrm{nm}$, sendo que o grupo 3 foi o que possuiu o menor tempo de exposição e o maior decréscimo de bilirrubina sérica (Meritano, et al., 2012). O outro estudo não especificou as irradiâncias das fototerapias convencional e LED, mas constatou que os recém- 
nascidos expostos ao LED obtiveram melhor desempenho no tratamento (Hamidi et al.; 2018).

Entre os efeitos encontrados na fototerapia, têm-se a variabilidade da frequência cardíaca (VFC) em recém-nascidos ictéricos em repouso com temperatura controlada nas incubadoras em fototerapia convencional. As análises apenas dos níveis séricos de bilirrubina não identificaram relação significativa com a VFC, entretanto, foram detectadas amostras significativas do aumento da frequência cardíaca no momento do uso da fototerapia convencional e em até 30 minutos após a realização do tratamento (Uhrikova, et al.; 2015).

Em relação ao estresse oxidativo, os estudos trazem evidências que afirmam que tanto a fototerapia convencional quanto a fototerapia de LED aumentam o índice de estresse oxidativo (OSI), assim como do estresse oxidativo total (TOS) tanto em recém-nascidos ictéricos a termo e prematuros quanto em recém-nascidos com hiperbilirrubinemia hemolítica (Mokhtar, et al., 2019), também corroborando para que a capacidade antioxidante total (TAC) diminuísse a nível sérico em todos os estudos, com maior significância nos recém-nascidos sob fototerapia convencional (Kale, et al., 2013; Boskabadi, et al.; 2018; Mokhtar, et al., 2019). Foi achada relação significativa entre o TOS sérico aumentado e a fototerapia convencional com luzes fluorescentes azuis e a fototerapia intensiva por LED, porém a fototerapia por LED com almofada de fibra óptica não possuiu significância no aumento do TOS (Kale, et al., 2013).

Estudo separou os recém-nascidos que realizaram fototerapia convencional em quatro grupos, em que um grupo realizou apenas fototerapia, o segundo grupo recebeu fototerapia combinada com albumina intravenosa (IVALB), o terceiro grupo fototerapia combinada com imunoglobulina intravenosa (IVIG) e o quarto grupo fototerapia com IVALB e IVIG. Foi constatado que o nível sérico de albumina aumentou conforme a idade dos recém-nascidos e não se obteve variação durante a aplicação da fototerapia ou da fototerapia combinada com IVIG, contudo foi percebido um aumento da albumina na fototerapia combinada com IVALB. A globina diminuiu conforme a idade, entretanto foi identificado que a hiperbilirrubinemia, a fototerapia convencional e a administração de IVALB são fatores de risco que corroboram para o decrescimento dos níveis de globina em recém-nascidos com hiperbilirrubinemia, aumentando assim o risco de imunossupressão, principalmente em recém-nascidos com mais de 16 dias de vida (Zheng, et al.; 2019).

Em relação ao nível sérico de cálcio em recém-nascidos no uso de fototerapia, foi verificada uma redução dos níveis de cálcio estatisticamente significativa. Após 48 horas de exposição à fototerapia, 26,1\% dos recém-nascidos envolvidos na pesquisa desenvolveram hipocalcemia, sendo apenas 1,2\% deles hipocalcemia sintomática (Padippura, et al.; 2018). Uma das limitações do estudo em questão é o fato de apenas o cálcio sérico ter sido verificado, pois na realidade o cálcio ionizado é o responsável por verificar a hipocalcemia verdadeira, uma vez que é constatado que os níveis de cálcio sérico podem ser afetados pelos níveis séricos de albumina que não é influenciada pela fototerapia (Zheng, et al.; 2019). Um dos sintomas da hipocalcemia são as convulsões, podendo esse estudo (Padippura, et al.; 2018) estar corroborando com os resultados do estudo abaixo em que são encontradas evidências da relação entre a fototerapia e as crises convulsivas (Newman, et al., 2016).

Foi relacionado ao tratamento com fototerapia o risco aumentado de convulsões e/ou epilepsia, sendo constatado no estudo que há maior risco de crises convulsivas, cerca de $20 \%$, em recém-nascidos do sexo masculino. Entretanto, o mecanismo com o qual a fototerapia pode aumentar o risco de crises convulsivas não é claro. Já quanto aos casos de epilepsia, foi verificado um risco significativo de cerca de 2 a 7 casos por 1000 recém-nascidos ao longo de 10 anos (Newman, et al., 2016).

Em recém-nascidos após o tratamento com fototerapia foi encontrada uma alteração nos metabólitos, como a $\beta$ glicose, $\alpha$-glicose, valina, tirosina, fosfocolina, piruvato, trimetilamina, entre outros. Ao todo, foram 28 metabólitos alterados em comparação com os valores encontrados no período anterior à iniciação da fototerapia. Desses 28 metabólitos, 13 aumentaram como o lactato e os lipídios e outros 15 decaíram, sendo a glicose o mais relevante, demonstrando que a fototerapia prejudica diretamente o metabolismo energético do recém-nascido. Os níveis séricos de piruvato diminuídos 
fortalecem a teoria de que o piruvato é utilizado pelo metabolismo para produzir mais adenosina trifosfato (ATP) pela via glicolítica, elevando assim a produção de lactato, aumentando a gliconeogênese a fim de evitar o decréscimo de glicose. Já a redução dos níveis de lipoproteína de baixa densidade (LDL) pode ser causada pelo estresse fotodinâmico (Cai et al., 2016). Ainda assim, são necessários outros estudos na área para corroborar os achados e também investigar os níveis de metabólitos em recém-nascidos saudáveis.

Em relação ao nível sérico de interleucina-6 (IL) e contagem de leucócitos, foi descoberta uma diferença significativa de aumento dos níveis séricos de IL-6 e leucócitos após a exposição do recém-nascido à fototerapia. Considera-se que a fototerapia pode alterar a função imunológica do neonato (Zarkesh, et al.; 2019). A trombocitopenia foi associada aos recémnascidos tratados com fototerapia mediante avaliação dos níveis séricos em 24, 48 e 72 horas durante a exposição à luz. Detectou-se que em 24 horas em uso da fototerapia, cerca de 8,1\% dos recém-nascidos apresentavam trombocitopenia grave, tendo esse número aumentado conforme o tempo transcorrido do tratamento chegando à marca dos 33,3\% dos recém-nascidos acometidos após 72 horas de exposição. Também foi decaindo o número de recém-nascidos que não apresentavam nenhum grau de trombocitopenia, por volta de 50\%, atingindo cerca de 33\% dos pacientes. É importante salientar que nenhum recémnascido apresentou sintomas da baixa contagem de plaquetas (Sajid, et al.; 2016). Esses estudos também reforçam a ideia de que a fototerapia influencia no sistema imunológico do recém-nascido (Zarkesh, et.; al 2016; Sajid, et al.; 2016; Zheng, et al.; 2019).

Foi encontrado em dois estudos distintos a associação entre a fototerapia e o câncer, como as leucemias linfóide, mielóide e não linfóide, câncer no cérebro, fígado, rins, entre outros cânceres (Wickremasinghe, et al.; 2016; Newman, et al.; 2018). Um dos estudos realizou uma coorte de 499.621 recém-nascidos, totalizando 60 casos de câncer em recém-nascidos expostos à fototerapia. Entretanto, nesse estudo, não houve associação estatisticamente significativa entre a fototerapia e o câncer (Newman, et al.; 2018). Já outro estudo apresentou uma coorte de pouco mais de cinco milhões de recém-nascidos, encontrando uma incidência de câncer de 21,4 por 100.000 pessoas, constatando nas análises já ajustadas a associação de fototerapia e leucemia mielóide, câncer renal e outros cânceres (Wickremasinghe, et al.; 2016). Ambos os estudos ressaltaram que o risco de recém-nascidos ictéricos com Síndrome de Down e que realizaram tratamento com fototerapia é maior (Wickremasinghe, et al.; 2016; Newman, et al.; 2018). Cabe salientar que ambos os estudos, por serem retrospectivos com busca de dados em prontuários, não trouxeram a variável tempo definida.

Foram separados em três grupos distintos recém-nascidos com hiperbilirrubinemia que realizaram fototerapia (grupo 1), recém-nascidos com icterícia fisiológica sem necessidade de fototerapia (grupo 2) e recém-nascidos saudáveis (grupo 3), nos três grupos não foram encontradas diferenças em marcadores de danos ao ácido desoxirribonucléico (DNA) ou apoptose de linfócitos antes do grupo 1 ser exposto à fototerapia. Todavia, após a exposição do grupo 1 à fototerapia, foram realizadas novas coletas de amostras sanguíneas nos três grupos, em que se evidenciou o aumento dos marcadores de danos ao DNA, aumento dos níveis de P53, induzindo a apoptose de linfócitos do sangue periférico nos integrantes do grupo 1 expostos à fototerapia. Constatou-se então que a hiperbilirrubinemia não influencia no dano ao DNA e nem na apoptose dos linfócitos do sangue periférico. Um fato relevante nesse estudo foi a comparação nos três grupos diferentes (Yahia, et al., 2015).

Além disso, foram vários os achados de hipertermia em recém-nascidos expostos à fototerapia e de outros efeitos adversos como as fezes amolecidas e erupções cutâneas (Yahia, et al., 2015; Cai, et al., 2016; Donneborg, et al, 2018; Luciano, et al., 2019; Mokhtar, et al., 2019).

Destaca-se evidências que apontaram o uso indiscriminado da fototerapia, principalmente em recém-nascidos que estão com os níveis de bilirrubina elevados, mas que ainda não atingiram os níveis recomendados para o início da fototerapia. Levando em consideração os riscos que esse tratamento acarreta, deve sempre ser utilizado com cuidado (Kale, et al., 2013; Yahia, et al., 2015; Wickremasinghe, et al.; 2016; Newman, et al.; 2018; Zheng, et al,; 2019), evitando a fototerapia 
desnecessária especialmente nos recém-nascidos portadores da Síndrome de Down (Newman, et al.; 2018).

\section{Conclusão}

As evidências científicas encontradas acerca das características e efeitos da fototerapia em recém-nascidos demonstraram que é importante avaliar criteriosamente o seu uso, principalmente em recém-nascidos que, em muitos casos, ainda não possuem a maturidade completa de todos os sistemas.

Vale ressaltar que a fototerapia, apesar de ser um tratamento caro devido ao alto custo dos aparelhos, é utilizada em todo o mundo em larga escala, até mesmo em países mais pobres conforme apontado pelos estudos selecionados. Apesar da fototerapia ser benéfica, pois degrada a bilirrubina sérica evitando complicações como a Síndrome de Kernicterus, o uso indiscriminado deve ser revisto, evitando a realização de sessões de fototerapia em casos que a bilirrubina ainda não tenha atingido os níveis recomendados pelos órgãos de saúde responsáveis, como a American Academy of Pediatrics e, no Brasil, o Ministério da Saúde.

Em relação aos aparelhos de fototerapia utilizados nos estudos, é possível afirmar que os aparelhos de LED obtiveram melhor desempenho em relação aos aparelhos de fototerapia convencional. Os resultados de depuração da bilirrubina sérica e o tempo de exposição do recém-nascidos à fototerapia foram melhores quando utilizado o aparelho de LED. Os aparelhos de LED duplo obtiveram melhores resultados no decréscimo dos níveis séricos de bilirrubina e menor tempo de exposição em comparação com os aparelhos de LED simples. Também é possível afirmar que, a fototerapia intermitente alcançou um declínio maior dos níveis de bilirrubina e menor tempo de duração do tratamento do que a fototerapia contínua.

Foi possível constatar que há a ocorrência de efeitos nocivos relacionados à fototerapia, tais como: aumento da frequência cardíaca, crises convulsivas, hipocalcemia, alterações no metabolismo, trombocitopenia, aumento de leucócitos, dano ao DNA. Também há vários estudos que sugerem que a fototerapia altera o funcionamento do sistema imunológico no recém-nascido, causa hipertermia, amolecimento das fezes e erupções cutâneas.

Portanto, a qualificação dos profissionais da saúde é fundamental, principalmente da enfermagem, pois ela atua diretamente nesse cuidado, para que haja a redução dos efeitos adversos da fototerapia e seja utilizada com responsabilidade. Vislumbra-se que com este estudo seja possível promover o uso seguro da fototerapia nas unidades de saúde.

A partir das evidências encontradas, sugere-se que pesquisas e ações de extensão sejam realizadas com profissionais e famílias, na direção de disseminar esse conhecimento científico. Sugere-se, na área da pesquisa, realizar mais estudos qualitativos para conhecer o que os profissionais e familiares sabem sobre as características e efeitos da fototerapia e na extensão a criação/disponibilidade de espaços de discussão sobre o tema.

\section{Referências}

Brasil. Ministério da Saúde (2011). Atenção à saúde do recém-nascido: guia para os profissionais de saúde. Brasil. Ministério da Saúde. Secretaria de Atenção à Saúde. Departamento de Ações Programáticas e Estratégicas. Brasília: Ministério da Saúde (Série A. Normas e Manuais Técnicas).

Boskabadi, H.; Molaei, M. K.; \& Zakerihamidi, M. (2018). Effect of phototherapy on pro-oxidant/antioxidant balance in newborns with Jaundice. Biomedical Research and Therapy, 5(7):2432-2439. 10.15419/bmrat.v5i7.455

Cai, A., Qi, S., Su, Z., Shen, H., Yang, Y., Cai, W., \& Dai, Y. (2016). A Pilot Metabolic Profiling Study of Patients with Neonatal Jaundice and Response to Phototherapy. Clinical and Translational Science, 9(4):216-20. 10.1111/cts.12401

Campbell Wagemann, S., \& Mena, P. (2019). Hiperbilirrubinemia severa en Recién Nacidos, factores de riesgo y secuelas neurológicas. Revista Chilena de Pediatría, 90(3): 267-274. 10.32641/rchped.v90i3.772

Carrasco Tejerina, S. (2016). Prevalencia de Ictericia Neonatal, Hiperbilirrubinemia intermedia y factores asociados en Recién nacidos a término en el Hospital II Ramón Castilla - EsSalud durante el año 2014. Universidad Ricardo Palma.

Colindres, J. V. et al., (2012). Prospective randomized controlled study comparing low-cost LED and conventional phototherapy for treatment of neonatal hyperbilirubinemia. Journal of Tropical Pediatrics, 8(3):178-83. 10.1093/tropej/fmr063. 
Donneborg, M. L., Vandborg, P. K., Hansen, B. M., Rodrigo-Domingo, M., \& Ebbesen, F. (2018). Double versus single intensive phototherapy with LEDs in treatment of neonatal hyperbilirubinemia. Journal of Perinatology, 38(2):154-158. 10.1038/jp.2017.167

Fernandes, J. I. S. (2018) Maternagem de mulheres-mães com filho submetido à fototerapia: contribuições para enfermagem. Dissertação de mestrado. Universidade Federal do Estado do Rio de Janeiro.

Hamidi, M., \& Aliakbari, F. (2018). Comparison of Phototherapy with Light-Editing Diodes (LED) and Conventional Phototherapy (Fluorescent Lamps) in Reducing Jaundice in Term and Preterm Newborns. World Family Medicine/Middle East Journal of Family Medicine, 16(3):123-128. 10.5742/MEWFM.2018.93319

Kale, Y., Aydemir, O., Celik, Ü., Kavurt, S., Isikoglu, S., Bas, A. Y., \& Demirel, N. (2013). Effects of phototherapy using different light sources on oxidant and antioxidant status of neonates with jaundice. Early Human Development, 89(12):957-60. 10.1016/j.earlhumdev.2013.09.013

Luciano, R., Mancini, G., Cota, F., Romano, A., Purcaro, V., Lerro, F., Vento, G. (2019). New high intensity fibreoptic phototherapy devices in healthy newborns: A single pad wrapped around the neonate body in comparison with a double pad device. Italian Journal of Pediatrics. $45(1): 68$. 10.1186/s13052019-0663-5

Melnyk, B.M.; Fineout-Overholt, E. (2011). Evidence-Based Practice in Nursing \& Healthcare: A Guide to Best Practice (2a ed.) Wolteres Kluwer.

Meritano, J. et al., (2012). Comparación de la eficacia de la fototerapia convencional con tubos de luz azul vs. LEDs. Rev. Hosp. Mat. Inf. Ramón Sardá, 2012;31(2): 57-62. Disponível em: https://www.redalyc.org/articulo.oa?id=91224139002

Mokhtar, W. A., Sherief, L. M., Elsayed, H., Shehab, M. M., El Gebaly, S. M., Khalil, A. M. M.,Kamal, N. M. (2019). Conventional intensive versus LED intensive phototherapy oxidative stress burden in neonatal hyperbilirubinaemia of haemolytic origin. Paediatrics and International Child Health, 40(354):1-5. $10.1080 / 20469047.2019 .1586185$

Newman, T. B., Wickremasinghe, A. C., Walsh, E. M., Grimes, B. A., Mcculloch, C. E., \& Kuzniewicz, M. W. (2016). Retrospective cohort study of phototherapy and childhood cancer in Northern California. Pediatrics, 137(6):e20151354. 10.1542/peds.2015-1354

Newman, T. B., Wu, Y. W., Kuzniewicz, M. W., Grimes, B. A., \& McCulloch, C. E. (2018). Childhood seizures after phototherapy. Pediatrics, 142(4): e20180648. https://doi.org/10.1542/peds.2018-0648

Organização Mundial da Saúde. (2018). Nascimentos prematuros. Disponível em: https://www.who.int/es/news-room/fact-sheets/detail/preterm-birth.

Padippura, M. Y., Mammen, D. S., Parameswaran, J., \& Vadakkedam, S. S. (2018). Hypocalcaemia due to phototherapy in term neonates with neonatal hyperbilirubinemia. Journal of Evolution of Medical and Dental Sciences, 7(48):5207-5211. 10.14260/jemds/2018/1155

Ramachandran, A. (2016). Neonatal hyperbilirubinaemia. Paediatrics and Child Health, 26(4):162-168. https://doi.org/10.1016/j.paed.2015.12.002

Rebollar-Rangel, J. A., Escobedo-Torres, P., \& Flores-Nava, G. (2017). Etiología de ictericia neonatal en niños ingresados para tratamiento con fototerapia. Revista Mexicana de Pediatria, 84(3):88-91. Disponível em: www.medigraphic.com/rmp

Saadat, S. H., Naderi, S., Zare, S., Khalili, S., \& Goodarzi, R. (2018). Epidemiologic Study of Jaundice in Newborns with Jaundice in the First 24 hours of Birth in Children's Hospital and Shariati Hospital of Bandar Abbas in 2010-2014. Journal of Research in Medical and Dental Science, 6(1):113-117. $10.24896 /$ jrmds. 20186118

Sachdeva, M., Murki, S., Oleti, T. P., \& Kandraju, H. (2015). Intermittent versus continuous phototherapy for the treatment of neonatal non-hemolytic moderate hyperbilirubinemia in infants more than 34 weeks of gestational age: a randomized controlled trial. Eur J Pediatr, 174(2):177-81. 10.1007/s00431014-2373-8.

Sajid, A., Mahmood, T., Riaz, S., \& Nabi, S. G. (2016). Phototherapy in Hyperbilirubinemic Neonates; Does it Affect Platelet Count? Annals of King Edward Medical University, 22(3): https://doi.org/10.21649/akemu.v22i3.1405

Santos, A. L. S., Miller, C. S., \& Juvenato, E. L. (2018). Nursing care for the stereo newborn term in phototerapic treatment in the hospital environment. Revista Educação, Meio Ambiente e Saúde, 8(3):47-71. Disponível em: http://www.faculdadedofuturo.edu.br/revista1/index.php/remas/article/view/184

Uhrikova, Z., Zibolen, M., Javorka, K., Chladekova, L., \& Javorka, M. (2015). Hyperbilirubinemia and phototherapy in newborns: Effects on cardiac autonomic control. Early Human Development, 91(6):351-6. 10.1016/j.earlhumdev.2015.03.009.

Whittemore R, Knafl K. The integrative review: update methodology. (2005). J Adv Nurs, 52(5):546-53. 10.1111/j.1365-2648.2005.03621.x.

Wickremasinghe, A. C., Kuzniewicz, M. W., Grimes, B. A., Mcculloch, C. E., \& Newman, T. B. (2016). Neonatal phototherapy and infantile cancer. Pediatrics, 137(6):e20151353-e20151353. 10.1542/peds.2015-1353

Yahia, S., Shabaan, A. E., Gouida, M., El-Ghanam, D., Eldegla, H., El-Bakary, A., \& Abdel-Hady, H. (2015). Influence of hyperbilirubinemia and phototherapy on markers of genotoxicity and apoptosis in full-term infants. Eur J Pediatr, 174: 459-464. https://doi.org/10.1007/s00431-014-2418-Z

Zarkesh, M., Dalili, S., Fallah, M., Heidarzadeh, A., \& Rad, A. (2016). The effect of neonatal phototherapy on serum level of interlukin-6 and white blood cells' count. Journal of Clinical Neonatology, 5(3) 189-192. https://www.jcnonweb.com/text.asp?2016/5/3/189/191260

Zheng, J., Wei, C., Zhao, M., \& Zhao, D. (2019). Phototherapy is associated with the decrease in serum globulin levels in neonatal hyperbilirubinemia. Biomedical Reports, 10(1): 63-69. 10.3892/br.2018.1166 